\title{
PENINGKATAN PRODUKTIVITAS PADA LINE ASSEMBLY STOPPER CRASH STOP DENGAN LINE BALANCING
}

\author{
Qomarotun Nurlaila \\ Dosen Tetap Prodi Teknik Mesin Universitas Riau Kepulauan Batam
}

\begin{abstract}
PT. XYZ is manufacturing company, it produces HDD (Hard Disk Drive) components with plastics and rubber material. One of HDD products which used rubber material is Stopper Crash Stop, it's produced by assembly process. The actual productivity from July - September 2013 indication that have average productivity is less than the standard. The actual productivity is $8,949 \mathrm{Pcs} / \mathrm{man} /$ day, but the standard productivity is $10,350 \mathrm{Pcs} / \mathrm{man} /$ day. The Main Root Causes, which contribute to productivity of assembly line of Stopper Crash Stop less than the standard are workplace that more than range of operator's hand, time of machines operation are different, work load are not balanced. And to increase the productivity of assembly line Stopper Crash Stop to achieve the standard done by Kaizen concept in phases and sustainable. $1^{\text {st }}$ kaizen is layout kaizen, re-layout table of vibration machine by make sit position of operator A and operator B is equal. $2^{\text {nd }}$ kaizen is machine kaizen, standardize time of machines operation refers to the fasters one. $3^{\text {rd }}$ kaizen is layout kaizen, optimize wide of table for vibration machine. And $4^{\text {th }}$ kaizen is line balancing kaizen, make work load of operator is balance. The Productivity before kaizen is 8,949 Pcs/man/day and the productivity after kaizen is 12,323 Pcs/man/day (the productivity increases 38\%).
\end{abstract}

Key words: Assembly, Productivity, Standard, Kaizen, Layout, Line balancing,

\section{Pendahuluan}

Untuk menjadi perusahaan kelas dunia, sebuah perusahaan harus mempunyai kemampuan bersaing, yaitu bersaing dengan perusahaan area bisnis sejenis, bersaing dengan pemain baru, bersaing dengan adanya produk pengganti, bersaing dengan daya tawar pembeli dan juga bersaing dengan daya tawar pemasok. Dan untuk bersaing diperdagangan dunia, perusahaan dituntut untuk bisa memproduksi produk atau jasa dengan kualitas terbaik, dengan biaya terendah dan dengan pengiriman tercepat. Sehingga perusahaan akan mempunyai tingkat daya saing yang besar dan akan menarik minat pelanggan.

Salah satu faktor yang mempengaruhi daya saing dari sebuah perusahaan adalah produktivitasnya. Karena produktivitas bisa sebagai indikasi dari kualitas, harga jual dan kecepatan pengiriman produk atau jasa yang dihasilkan oleh perusahaan yang bersangkutan. Sehingga setiap perusahaan yang ingin tetap eksis dan bisa meningkatkan kemampuan daya saingnya perlu untuk meningkatkan produktivitasnya. Produktivitas dinyatakan meningkat ketika keluaran yang meningkat dengan masukan yang sama atau ketika keluaran yang sama meskipun terjadi pengurangan masukan.

Produktivitas untuk suatu perusahaan merupakan rasio dari keseluruhan keluaran (produk/jasa) dalam suatu periode dibagi dengan total masukan sumber daya (mencakup: manusia, teknologi, material, mesin, area produksi, dan sebagainya) yang digunakan selama periode yang sama. Penelitian dilakukan pada PT. XYZ, perusahaan yang bergerak dibidang manufakturing yang memproduksi komponen Hard Disk Drive (HDD) dengan bahan dasar plastik dan karet . Dan untuk penelitian ini difokuskan pada produk dengan bahan dasar karet, dengan beberapa alasan sebagai berikut:

1. Merupakan bisnis utama.

2. PT. XYZ unggul dalam pengembangan karet dibandingkan para pesaingnya.

3. Pesaing untuk produk karet lebih sedikit dibandingkan pesaing untuk produk plastik. 
4. Peluang pasar untuk produk karet lebih besar dibanding produk plastik.

Penelitian dilakukan pada line assembly Stopper Crash Stop karena diline assembly tersebut ditemukan pemborosan paling besar dibandingkan area yang lain. Rata-rata produktivitas aktual dari line assembly tersebut untuk bulan Juli - September 2013 hanya 8,949 buah/orang/hari, dimana lebih rendah dibandingkan standar 10,350 buah/orang/hari.

Sehingga untuk meningkatkan produktivitas line assembly tersebut diperlukan tindakan untuk mengurangi segala jenis pemborosan dan atau mengurangi cycle time dengan konsep kaizen. Dan konsep kaizen yang diterapkan pada penelitian ini adalah line balancing, dengan pertimbangan line balancing adalah konsep kaizen yang sering digunakan dan efektif untuk meningkatkan produktivitas line assembly.

\section{Metode}

Desain penelitian yang digunakan merupakan gabungan eksploratif dan deskriptif. Sedangkan pendekatan penelitiannya menggunakan data kuantitatif. Variabel penelitian ini adalah produktivitas, dengan jenis data yang digunakan adalah data primer dan data sekunder. Metode yang dilakukan untuk meningkatkan produktivitas pada line assembly Stopper Crash Stop adalah line balancing (kaizen). Berikut langkah-langkah yang dilakukan:

1. Mencari fenomena diarea produksi yang digunakan sebagai area penelitian.

2. Menentukan masalah yang akan dijadikan objek penelitian.

3. Kajian pustaka, mencakup kajian teori dan penelitian terdahulu.

4. Cek kondisi sekarang (data primer dan data sekunder).

5. Indentifikasi penyebab produktivitas lebih rendah dibandingkan standar.

6. Pilih penyebab-penyebab paling dominan, sehingga apabila ditangani maka produktivitas akan meningkat secara signifikan.

7. Lakukan perbaikan dengan konsep kaizen, perbaikan yang terus menerus.

8. Pengecekan keefektifan dari hasil perbaikan, jika belum ada peningkatan maka lakukan tindakan perbaikan lain sehingga akan didapatkan hasil perbaikan yang sinifikan.

9. Menentukan tema penelitian atau perbaikan berikutnya.

\section{Data dan Analisa}

\section{Pengenalan Produk dan Proses Assembly}

Produk Stopper Crash Stop merupakan salah satu komponen Hard Disk Drive yang diproduksi oleh PT. XYZ. Produk Stopper Crash Stop dibentuk dengan menggabungkan sebuah produk karet Crash Stop dan sebuah stainless, untuk penggabungannya menggunakan proses assembly yang didukung mesin semi auto.

Line assembly Stopper Crash Stop dirancang untuk dioperasikan oleh 2 orang operator setiap shift, sehingga jumlah operator setiap hari untuk line assembly tersebut adalah 4 orang. Dengan standar produktivitasnya adalah 10.350 buah/operator/hari.

Proses assembly Stopper Crash Stop didukung oleh 2 buah mesin assembly, sebuah mesin ball feeder, sebuah mesin penggetar, sebuah mesin ejektor, sebuah jig transfer, sebuah box WIP, sebuah box Finish Good, sebuah jig karet, dan sebuah jig shaft. Gambar 1 menunjukkan layout dari line assembly. 


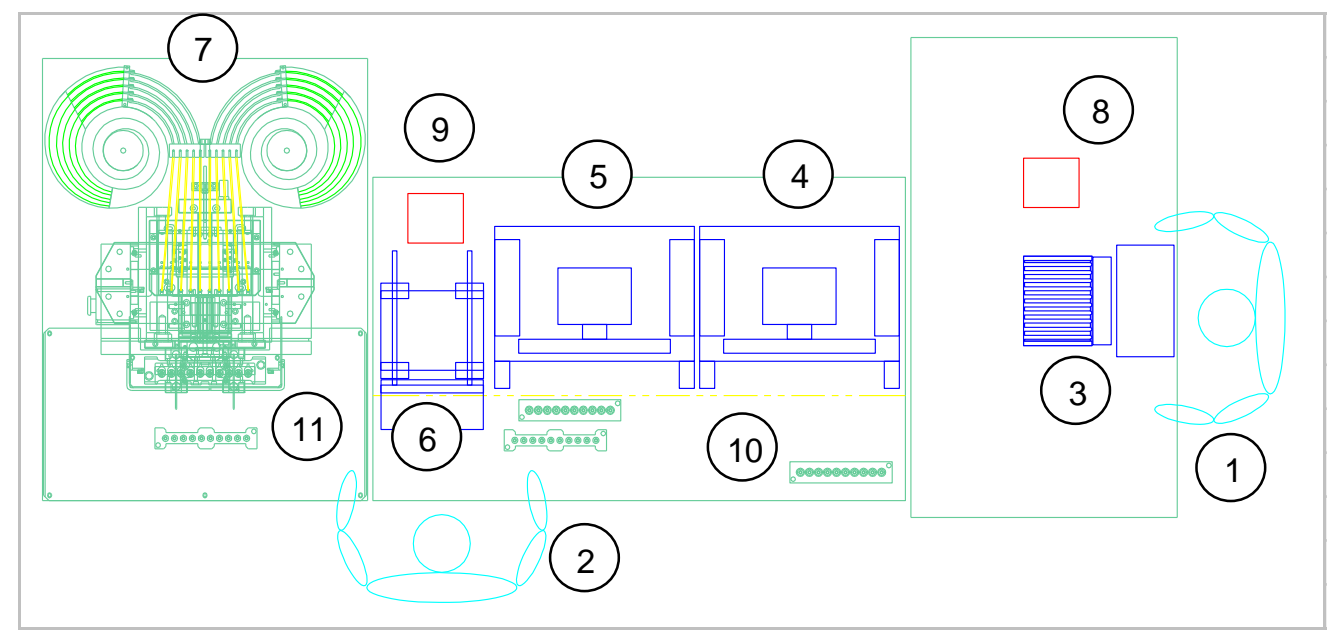

\section{Gambar 1. Layout sebelum kaizen}

Keterangan:

(1). Operator A; (2). Operator B; (3). Mesin penggetar dan jig transfer; (4). Mesin assembly no.1; (5). Mesin assembly no. 2; (6). Mesin ejektor; (7). Mesin Ball Feeder; (8). Box WIP karet; (9). Box Finish Good; (10). Jig karet; (11). Jig shaft

\section{Identifikasi Masalah}

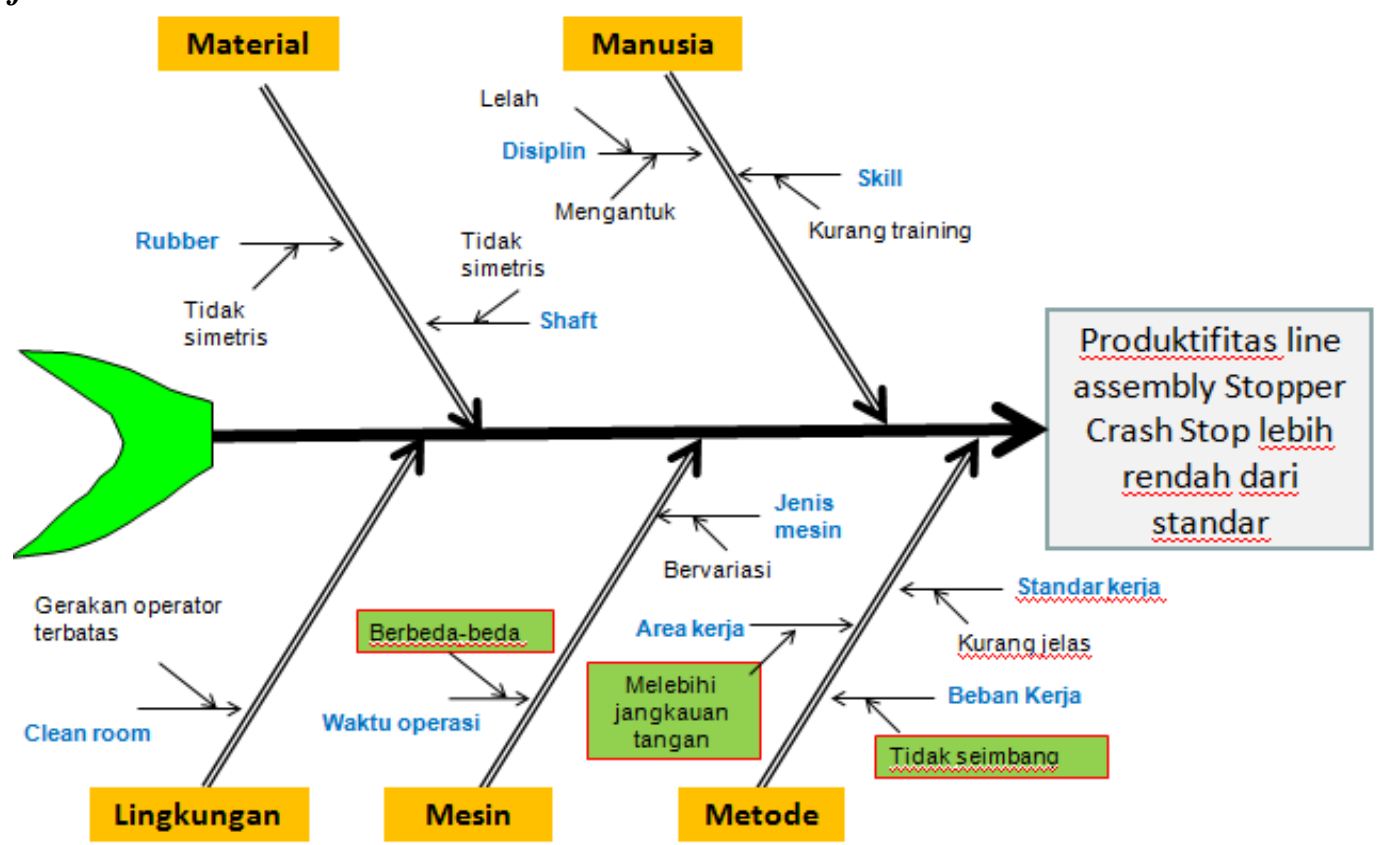

Gambar 2. Diagram tulang ikan

Dari gambar 2 ditunjukkan bahwa: Permasalahan yang dihadapi adalah produktivitas line assembly Stopper Crash Stop lebih rendah dari standar dan akar masalah yang akan ditangani antara lain:

1. Area kerja yang melampaui jangkauan tangan

Dari gambar 1, bisa dilihat bahwa area kerja dari operator B lebih luas dibandingkan area kerja dari operator A. Operator B mencakup area dari mesin ball feeder, mesin ejektor dan 2 buah mesin assembly, sedangkan operator A hanya mencakup area mesin penggetar saja. Karena area kerjanya yang luas, operator B perlu untuk menjulurkan tangannya untuk mencapai salah satu ujung dari area kerjanya, sehingga dalam hal ini bisa disimpulkan bahwa area kerja dari operator B melebihi jangkauan tangan atau terjadi pemborosan gerakan. Sehingga untuk 
menghilangkan pemborosan tersebut perlu dilakukan kaizen layout dengan mere-layout line assembly tersebut.

2. Waktu operasi mesin yang berbeda-beda

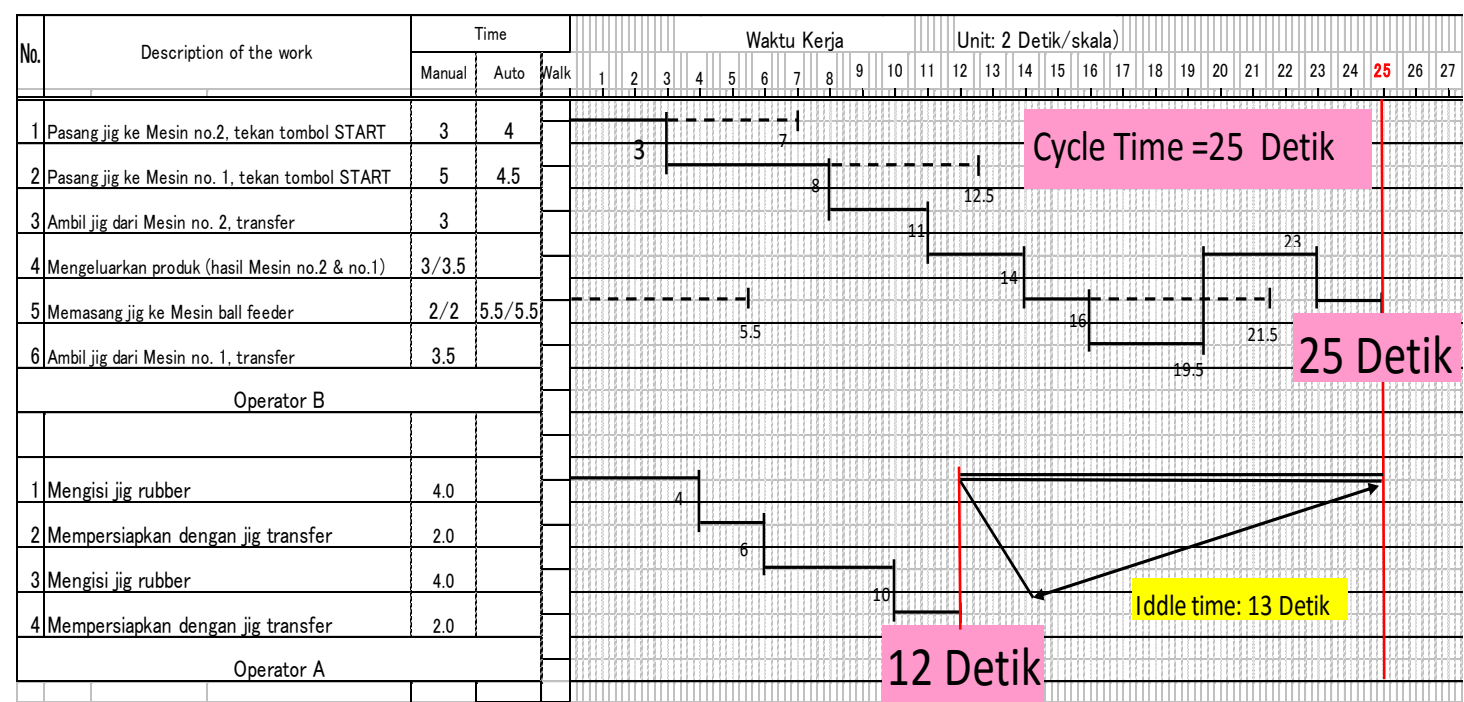

Gambar 3. Work combination sheet dari kondisi sebelum kaizen

Gambar 3 menunjukkan hasil pengecekan cycle time kondisi sebelum kaizen dapat dilihat :

a. Cycle time line assembly adalah 25 detik, dengan cycle time operator A sebesar 12 detik dan cycle time operator B sebesar 25 detik. Sehingga untuk meningkatkan produktivitas perlu dilakukan kaizen.

b. Waktu pekerjaan manual dari mesin assembly no.1 lebih lama dibandingkan mesin assembly no.2. Sehingga untuk meningkatkankan produktivitas perlu untuk dilakukan kaizen layout.

c. Waktu operasi mesin yang digunakan pada line assembly tersebut berbeda-beda (tidak standar): waktu operasi dari mesin assembly no. 1 adalah 4.5 detik, waktu operasi dari mesin assembly no. 2 adalah 4 detik dan waktu operasi dari mesin ball feeder adalah 5.5 detik. Sehingga untuk meningkatkan produktivitasnya perlu dilakukan kaizen mesin.

\section{Beban kerja tidak seimbang}

Total langkah dari proses assembly Stopper Crash Stop adalah 11 langkah, dimana 3 langkah dilakukan oleh operator A dan 8 langkah lainnya dilakukan oleh operator B. Dengan demikian beban kerja operator A dan B tidak seimbang, sehingga perlu untuk dilakukan penyeimbangan beban kerja antara operator A dan operator B. Tabel 1 menunjukkan langlah-langkah dari proses assembly.

\section{Pembahasan}

Berdasarkan analisa terhadap kondisi sebelum kaizen, maka ditawarkan solusi untuk setiap akar pemasalahan. Tabel 2 menunjukkan hubungan akar masalah dan solusi yang ditawarkan.

Tabel 1. Langkah-langkah proses assembly Stopper Crash Stop

\begin{tabular}{|c|c|c|c|}
\hline \multirow{2}{*}{ Langkah } & Pekerjaan & Operato & Operat \\
& & r A & or B \\
\hline
\end{tabular}




\begin{tabular}{|c|l|c|c|}
\hline 1 & $\begin{array}{l}\text { Mengisi karet ke tray yang dipasang diatas mesin penggetar, } \\
\text { sehingga produk akan tersusun dan siap untuk dimasukkan ke } \\
\text { jig transfer }\end{array}$ & $\mathrm{X}$ & - \\
\hline 2 & Mengisikan karet ke jig transfer & $\mathrm{X}$ & - \\
\hline 3 & Mentransfer karet dari jig transfer ke jig karet & $\mathrm{X}$ & - \\
\hline 4 & $\begin{array}{l}\text { Mengisikan shaft ke jig shaft dengan menggunakan mesin ball } \\
\text { feeder }\end{array}$ & - & $\mathrm{X}$ \\
\hline 5 & $\begin{array}{l}\text { Gabungkan jig shaft dan jig karet, dengan jig shaft diposisi } \\
\text { atas }\end{array}$ & - & $\mathrm{X}$ \\
\hline 6 & $\begin{array}{l}\text { Pasangkan jig karet \& jig shaft kemesin } \text { assembly, tekan } \\
\text { tombol START }\end{array}$ & - & $\mathrm{X}$ \\
\hline 7 & Ambil jig karet \& jig shaft dari mesin assembly & - & $\mathrm{X}$ \\
\hline 8 & Pisahkan jig karet \& jig shaft & - & $\mathrm{X}$ \\
\hline 9 & Pindahkan jig karet ke operator A & - & $\mathrm{X}$ \\
\hline 10 & Pindahkan jig shaft ke jig ejektor, keluarkan produk & $\mathrm{X}$ \\
\hline 11 & Pindahkan jig shaft ke mesin ball feeder & 8 \\
\hline & Total & - & - \\
\hline
\end{tabular}

Sumber : Pengamatan langsung

Tabel 2. Hubungan akar masalah dan solusi kaizen yang ditawarkan

\begin{tabular}{|l|l|l|}
\hline \multicolumn{1}{|c|}{ Kondisi sekarang } & \multicolumn{1}{|c|}{$\begin{array}{c}\text { Praduga akar } \\
\text { masalah }\end{array}$} & \multicolumn{1}{|c|}{ Solusi } \\
\hline Area kerja operator B lebih luas dibanding operator A & $\begin{array}{l}\text { Layout kurang } \\
\text { optimal }\end{array}$ & Re-layout \\
\hline $\begin{array}{l}\text { Waktu pekerjaan manual dari mesin assembly no.1 lebih } \\
\text { lama dibanding mesin assembly no. 2 }\end{array}$ & $\begin{array}{l}\text { Layout kurang } \\
\text { optimal }\end{array}$ & Re-layout \\
\hline Waktu operasi mesin berbeda & $\begin{array}{l}\text { Waktu operasi } \\
\text { mesin tidak } \\
\text { diperhatikan saat } \\
\text { set up mesin }\end{array}$ & $\begin{array}{l}\text { Standarisasi } \\
\text { waktu } \\
\text { operasi } \\
\text { mesin }\end{array}$ \\
\hline $\begin{array}{l}\text { Cycle time operator B (25 detik) lebih lama dibanding } \\
\text { operator A (12 detik) }\end{array}$ & $\begin{array}{l}\text { Beban kerja tidak } \\
\text { seimbang }\end{array}$ & $\begin{array}{l}\text { Line } \\
\text { Balancing }\end{array}$ \\
\hline $\begin{array}{l}\text { Beban kerja tidak seimbang, pekerjaan operator B lebih } \\
\text { komplek dibanding opertor A }\end{array}$ & $\begin{array}{l}\text { Beban kerja tidak } \\
\text { seimbang }\end{array}$ & $\begin{array}{l}\text { Line } \\
\text { balancing }\end{array}$ \\
\hline
\end{tabular}

\section{Perbaikan ke-1: Kaizen Layout}

Dilakukan dengan mere-layout meja mesin penggetar dengan mensejajarkan posisi duduk operator A dan operator B. Gambar 4 menunjukkan layout sebelum perbaikan ke-1 dan gambar 5 menunjukkan layout setelah perbaikan ke-1. 


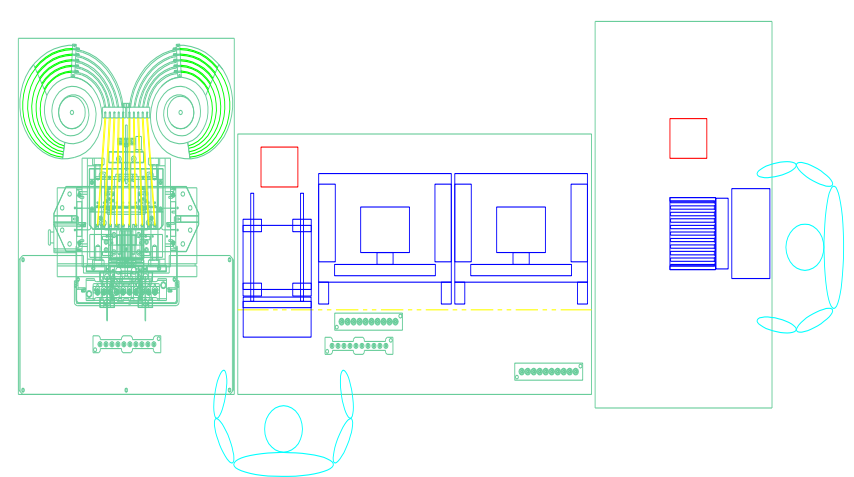

Gambar 4. Layout sebelum perbaikan ke-1 (kaizen layout)

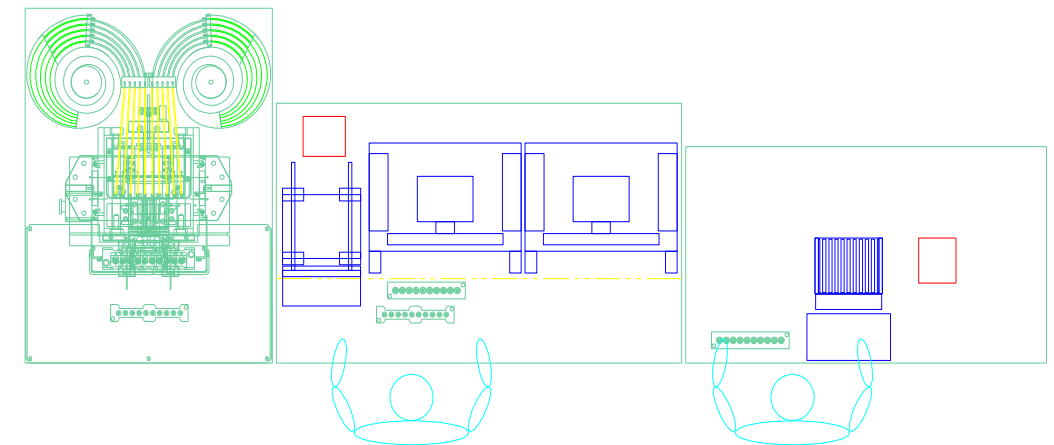

Gambar 5. Layout setelah perbaikan ke-1 (kaizen layout)

Efek dari perbaikan ke-1 antara lain:

a. 8 waktu pekerjaan manual berkurang masing-masing sebesar 0.5 detik.

b. Cycle time line assembly berkurang 4 detik, dari 25 menjadi 21 detik.

Hasil perbaikan masih belum signifikan \& beban kerja antar operator masih belum seimbang, sehingga perlu dilakukan kaizen berikutnya.

\section{Perbaikan ke-2: Kaizen Mesin}

Dilakukan dengan menstandarkan waktu operasi mesin dengan mengacu pada waktu operasi mesin yang paling cepat (waktu operasi mesin assembly no. 2, yaitu 4 detik. Penstandaran waktu operasi mesin dilakukan dengan mengoptimalkan pergerakan mesin dengan tidak mempengaruhi kualitas dari produk.

Efek dari perbaikan ke-2 adalah waktu operasi dari mesin assembly dan ball feeder sama, yaitu 4 detik. Sedangkan cycle time dari line assembly tetap sama seperti sebelum kaizen ke-2. Hasil perbaikan masih belum signifikan sehingga perlu dilakukan kaizen berikutnya.

\section{Perbaikan ke-3: Kaizen Layout}

Dilakukan dengan mengoptimalkan luas meja untuk mesin penggetar dengan memodifikasi/memotong meja dari ukuran 890 x $500 \mathrm{~mm}$ menjadi 350 x $500 \mathrm{~mm}$. Gambar 5 menunjukkan layout sebelum perbaikan ke-3 (setelah perbaikan ke-1) dan gambar 6 menunjukkan layout setelah perbaikan ke-3. 


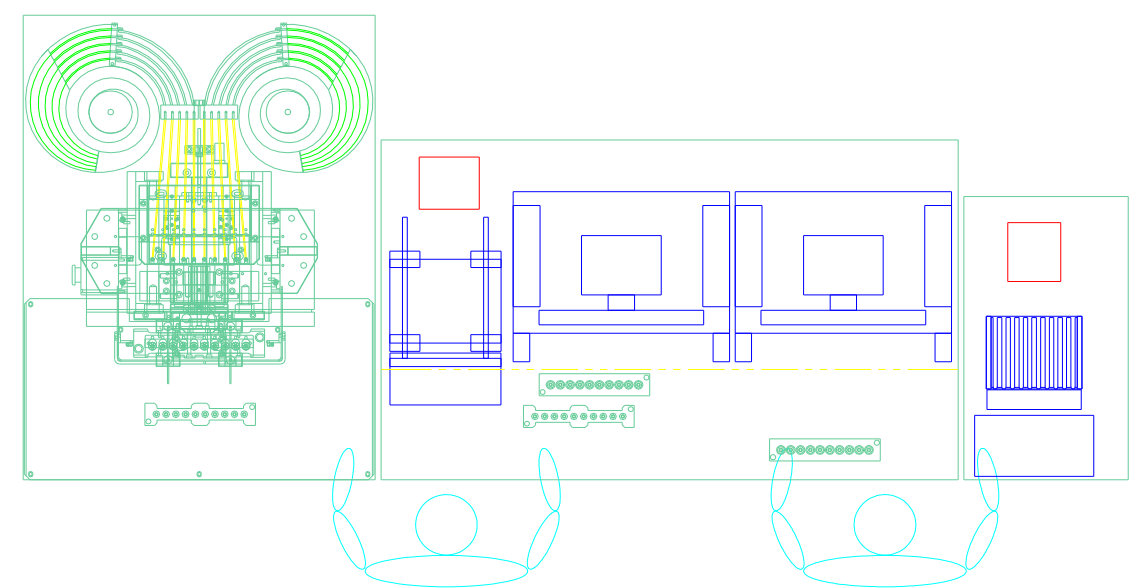

Gambar 6. Layout setelah perbaikan ke-3 (kaizen layout)

Efek dari perbaikan ke-1 antara lain:

a. 2 waktu pekerjaan manual berkurang masing-masing sebesar 0.5 detik.

b. Cycle time line assembly berkurang 0.5 detik, dari 21 menjadi 20.5 detik.

Hasil perbaikan masih belum signifikan sehingga perlu dilakukan kaizen berikutnya.

\section{Perbaikan ke-4: Kaizen Line Balancing}

Dilakukan dengan menyeimbangkan beban kerja dari kedua operator, yaitu dengan menyerahkan beberapa pekerjaan operator B ke operator A. Untuk memperlancar perbaikan ini diperlukan penambahan sebuah jig karet dan sebuah jig shaft.

Efek dari perbaikan ke-4 antara lain:

a. 2 pekerjaan manual berkurang (pekerjaan operator B yang diserahkan ke operator A).

b. Beban kerja operator seimbang, cycle time dari masing-masing operator adalah 16 detik.

c. Cycle time line assembly berkurang 4.5 detik, dari 20.5 menjadi 16 detik.

d. Keluaran per cycle bertambah 5 buah, dari 10 menjadi 15 buah.

Hasil perbaikan sudah signifikan dan beban kerja operator sudah seimbang.

\section{Hasil Kaizen}

Kaizen dapat meningkatkan produktivitas line assembly Stopper Crash Stop mencapai standar, dengan peningkatan sebesar 38\%. Perbandingan data sebelum dan setelah kaizen ditunjukkan pada tabel 3. Perbandingan produktivitas antara standar, sebelum dan sesudah kaizen ditunjukkan pada gambar 7.

Dalam penelitian ini digunakan 22 penelitian terdahulu sebagai referensi. Dari persamaan dan perbedaan penelitian ini dengan penelitian terdahulu maka dapat diambil kesimpulan bahwa:

1. Line balancing dapat digunakan untuk meningkatkan produktivitas dari line produksi (baik assembly atau fabrikasi) dan

2. Line balancing dapat diterapkan disegala bidang usaha antara lain: elektronik, otomotif, footwear,textile, kontruksi, seluler, toner, minuman, dll.

Tabel 3. Perbandingan data sebelum dan setelah kaizen

\begin{tabular}{|c|c|c|}
\hline Deskripsi & Sebelum kaizen & Setelah kaizen \\
\hline Cycle time line assembly (detik) & 25 & 16 \\
\hline
\end{tabular}




\begin{tabular}{|l|c|c|}
\hline Cycle time operator A (detik) & 12 & 16 \\
\hline Cycle time operator B (detik) & 25 & 16 \\
\hline Iddle time (detik) & 13 & 0 \\
\hline Produktivitas (buah/orang/hari) & 8,949 & 12,323 \\
\hline
\end{tabular}

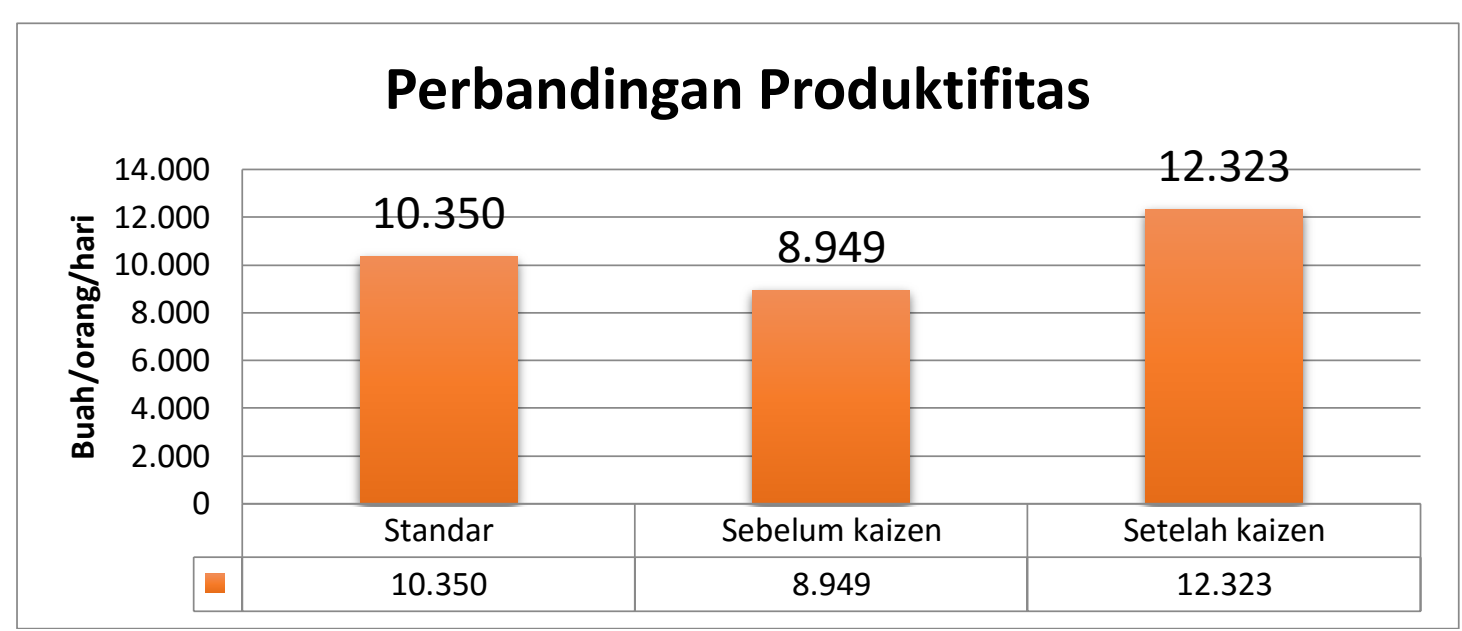

Gambar 7. Grafik perbandingan standar, sebelum kaizen dan setelah kaizen

\section{Kesimpulan dan Saran}

Dari penelitian yang telah dilakukan maka bisa diambil kesimpulan dan diberikan saran untuk perbaikan selanjutnya.

\section{Kesimpulan}

1. Tujuan penelitian tercapai yaitu meningkatkan produktivitas line assembly Stopper Crash Stop mencapai standar.

2. Akar masalah yang paling dominan mempengaruhi produktivitas line assembly Stopper Crash Stop adalah area kerja yang melampaui jangkauan tangan, waktu operasi mesin yang berbeda-beda dan beban kerja tidak seimbang.

3. Produktivitas line assembly Stopper Crash Stop ditingkatkan dengan konsep kaizen yaitu kaizen layout, mesin dan line balancing, dengan peningkatan produktivitas $38 \%$.

\section{Saran}

1. Merubah target produktivitas line assembly Stopper Crash Stop ke 12,323 buah/orang/hari.

2. Menerapkan langkah-langkah dan cara peningkatan produktivitas ke lain produksi yang serupa.

\section{Daftar Pustaka}

Bailey, B.D \& Liu, P.C (1998). Electronics Manufacturing Company Hand Assembly Productivity Improvement, Industrial Technology, 15 (1), 1-4.

Chakraborty, A., dkk (2013), Importance of Kaizen Concept in Medium manufacturing Enterprises, International Journal of Management and Strategy, 4 (6), 1-11.

Chen, J. C., dkk, A Kaizen Based Approach for Cellular Manufacturing System Design: A Case Study, The Journal of Technology Studies, $19-27$.

Emeke, O. \& Offiong, A. (2013), Productivity Improvement in Breweries Through Line Balancing Using Heuristic Method, International Journal Publications Of Problems \& Application In Engineering Research,04 (01), 19-26. 
Gautam, R., dkk (2012), Kaizen Implementation in an Industry in India: A Case Study, International Journal of Research in Mechanical Engineering \& Technology, 2 (1), 25 - 33.

Gomes, F. C. (2010), Managemen Sumber Daya Manusia, Yogyakarta: Andi Offset.

Handoko, T.H. (2008), Dasar-Dasar Manajemen Produksi dan Operasi (Edisi 1), Yogyakarta: BPFE.

Hemanand, H., dkk, Improving productivity of manufacturing division using lean concepts and development of material gravity feeder-a case study, Lean Thinking, 3 (2), 117-134.

Ikuma, L. H., dkk (2011), Use of Safety and Lean Integrated Kaizen to Improve Performance in Modular Homebuilding, Journal of Contruction Engineering and Management, 551 - 560.

Imai, M (2012), Gemba Kaizen: A Commonsense Approach To Continuous Improvement Strategy, ( $2^{\text {nd }}$ edition), New York: McGraw-Hill.

Indrawan, Y \& Hariastuti, N.L.P (2012), Minimalisasi bottleneck proses produksi dengan menggunakan metode line balancing, Jurusan Teknik Industri, Institut Teknologi Adhi Tama Surabaya.

James, J., dkk (2013), Productivity Improvement by Enhancing the Bottleneck Station in an Alternator Production Plant with Layout Improvement and Its Cost Analysis, International Journal of Scientific and Research Publications, 3 (9), 1-7.

Kadarisman, M. (2012), Managemen pengembangan sumber daya manusia, Jakarta: PT. Raja Grafindo Persada.

Kamlekar, N., dkk (2012), Implementation of Assembly Line Balancing in a Labour Intensive Manufacturing Unit, National Conference on Emerging Challenges for Sustainable Business, 1720-1730.

Komarudin \& Saputra, R. (2012), Peningkatan efisiensi dan produktivitas kinerja melalui pendekatan analisis rangked positional weight method PT. X, Teknik Industri, Institut Sains dan Teknologi Nasional, 1-8.

Kumar, N \& Mahto, D (2013). Productivity Improvement through Process Analysis for Optimizing Assembly Line in Packaging Industries, Global Journal of Researches in Engineering Industrial Engineering, 13 (3), 10-26.

Kusuma, H (2004), Managemen Produksi (Perencanaan dan Pengendalian Produksi), Yogyakarta: Andi Offset.

Lina Gozali, L., dkk (2012), Analisa keseimbangan lini pada departemen Chassis PT Toyota Motor Manufacturing Indonesia dengan algoritma ant colony, rank positional weight, dan algoritma genetika, Jurnal Teknik Industri, 119-126

Mandwe, P (2013), Productivity Improvement Of Crankshaft, Scientific \& Technology Research, 2 ( 7), $207-209$.

Marri, H.B. \& Shaikh, G.Y. (2012), The Role of Productivity Improvement Tools and Techniques in the Textile Sector during Manufacturing, Proceedings of the 2012 International Conference on Industrial Engineering and Operations Management Istanbul ( Turkey), 2570-2573.

Pandit, S. V., dkk (2014), Productivity Improvement by Application of Line Balancing, International Journal of Innovative Research in Science, Engineering and Technology, 3 (4), 11495 - 11502.

Pei, L. M. \& Tap, M. M. (2002), Improving productivity Through Line Balancing- A Case Study, Jurnal Mekanikal, 14, $48-62$.

Prasad, M. M., dkk (2013), An Optimal Balancing Of Multiple Assembly Line For A Batch Production Unit, International Journal of Lean Thinking, 4 (2), 22 - 32.

Rajenthirakumar, D. \& Thyla, P.R (2010), Quality and Productivity Improvement in Automotive Component Manufacturing Company Using Kaizen, 36-38.

Ramadhani, S (2012), Skripsi: Analisis Penerapan Konsep Penyeimbangan Lini (Line Balancing) Pada Sistem Produksi Percetakan harian Tribun di Makasar, Sulawesi: Universitas Hasanudin Makasar.

Rameez, H.M. \& Inamdar, K.H. (2010), Areas of Lean Manufacturing for Productivity Improvement in a Manufacturing Unit, World Academy of Science, Engineering and Technology, 45, 584-587.

Rivai, V. \& Sagala, E.J. (2013), Managemen sumber daya manusia untuk perusahaan, Jakarta: PT. Raja Grafindo Persada.

Roy, H.N., dkk, Productivity Improvement of a Fan Manufacturing Company by using DMAIC Approach: A SixSigma Practice, Global Journal of Researches in Engineering Industrial Engineering, 13 (4), 1-6.

Saeheaw, T., dkk (2009), Line Balancing in the Hard Disk Drive Process Using Simulation Techniques, World Academy of Science, Engineering and Technology, 3, 593 - 597.

Sihombing, H., dkk (2011), Line balancing Analysis of Tuner Product Manufacturing, International Journal of Engineering Science and Technology (IJEST), 3 (6), 5206 - 5214.

Sugiyono (2013), Metode penelitian kuantitatif dan kualitatif dan $R \& D$, Bandung: Alfabeta.

Sunyoto, D. (2013), Manajemen sumber daya manusia, Jakarta: CAPS (Center for Academic Publishing Service).

Uehira (2011), Seven waste (Hand book Improvement Training), Jepang: MPCJ. 